\title{
Variation in Phosphorus Availability, Root Architecture Attributes, and Onset of Storage Root Formation among Sweetpotato Cultivars
}

\author{
Arthur Villordon and Jeffrey C. Gregorie \\ Louisiana State University Agricultural Center Sweet Potato Research \\ Station, Chase, LA 71324
}

\section{Don LaBonte \\ Louisiana State University Agricultural Center School of Plant, Environmental, and Soil Sciences, 137 J.C. Miller Hall, Baton Rouge, LA 70803-2120}

Additional index words. Ipomoea batatas, anomalous cambium, storage root development, root architecture, lateral roots, phosphorus

\begin{abstract}
The primary objective of this work was to generate species-specific information about root architectural responses to variations in inorganic phosphate $(\mathrm{Pi})$ availability at the onset of storage root formation among six sweetpotato (Ipomoea batatas) cultivars. Three Pi levels were used: 0 (low Pi); 0.17 (medium Pi); and 0.34 (high Pi) g/pot triple super phosphate $(0 \mathrm{~N}-46 \mathrm{P}-0 \mathrm{~K})$. The check cultivar 'Bayou Belle' (BB) consistently showed evidence of storage root formation at 15 days in adventitious roots (ARs) grown across three Pi levels and two planting dates (PDs). Storage root formation was also detected in 'Orleans' $(\mathrm{OR})$ and 'Beauregard' $(\mathrm{BX})$, but it was less consistent relative to $B B$. In general, BB had the lowest adventitious root (AR) number relative to the other cultivars, but the magnitudes of difference varied with $P i$ availability and $P D$. With the first PD, BX had a 45\% higher AR number compared with BB in low Pi conditions; however, there were no differences in the second PD. Within cultivars, BX and Okinawa grown in low $P i$ showed combined $17 \%$ and $24 \%$ reductions in primary root length (PRL) relative to roots grown in high $\mathrm{Pi}$. BB had a higher lateral root number (LRN) and lateral root density (LRD) across Pi levels, corroborating prior data regarding the association of these root architectural attributes with the onset of storage root formation. The experimental data support the hypothesis regarding the existence of genetic variation for Pi efficiency in sweetpotato and that some well-documented Pi-efficient root traits like high LRN and LRD are indirectly selected for in-breeding programs that focus on early storage root formation and stable yields across environments.
\end{abstract}

There is increasing evidence that the availability of $\mathrm{Pi}$, the major form of phosphorus acquired by plants, is a key factor that limits crop productivity on a global scale.

\footnotetext{
Received for publication 10 Aug. 2020. Accepted for publication 16 Sept. 2020.

Published online 22 October 2020.

Approved for publication by the Director of the Louisiana Agricultural Experiment Station as manuscript number 2020-260-34821. Mention of trademark, proprietary product or method, and vendor does not imply endorsement by the Louisiana State University Agricultural Center nor its approval to the exclusion of other suitable products or vendors. Portions of this research were supported by Lamb Weston and the Louisiana Sweetpotato Advertising and Development Fund. This material is based on work that is supported by the National Institute of Food and Agriculture, U.S. Department of Agriculture, Hatch projects.

A.V. is the corresponding author. E-mail: avillordon@agcenter.lsu.edu.

This is an open access article distributed under the CC BY-NC-ND license (https://creativecommons. org/licenses/by-nc-nd/4.0/).
}

Low soil Pi availability has been associated with crop yield losses ranging from $25 \%$ to $60 \%$ (Crombez et al., 2019). Abiotic and biotic variables such as microbial activity, $\mathrm{pH}$, and cation quantity can limit Pi availability by promoting its conversion to forms that are not readily available to plants (Dixon et al., 2020). In addition, the relatively low mobility of Pi results in poor distribution in the soil. This contributes to inefficient $\mathrm{Pi}$ fertilization, with as low as $20 \%$ of $\mathrm{Pi}$ absorbed by plants in land recently converted for crops or pastures (Simpson et al., 2011). However, it is possible to increase Pi recovery in the range of $50 \%$ to $70 \%$ by optimizing application amounts based on critical soil Pi thresholds and optimization of placement relative to the root zone (Roberts and Johnston, 2015). Therefore, even though $\mathrm{Pi}$ is routinely applied in high-input agricultural systems, plants may be subjected to Pi deprivation due to low availability of this essential nutrient, especially if application amounts and placement are not optimized. Cumulative data from work involving the model plant Arabidopsis thaliana and wellcharacterized cereal crops have revealed that under conditions of low Pi availability, plants modulate root system architecture to maximize Pi uptake and positively influence yield (Lopez-Arredondo et al., 2014). These modifications include reduced primary root growth (Gutiérrez-Alanís et al., 2018), enhanced LRD (Niu et al., 2013), and increased number and length of root hairs (Parry, 2018). Other adaptations include the release of organic acids and symbiosis with mycorrhizal fungi that increases Pi foraging (Dixon et al., 2020). Crop-specific knowledge of root architecture traits that contribute to Pi efficiency is of fundamental importance. First, such information can contribute to the increased understanding of genotype and environmental interactions (Lobet et al., 2019). Second, it will lead to the identification of RSA traits that contribute to Pi efficiency, enabling the incorporation of these traits into breeding programs (Lopez-Arredondo et al., 2014).

In general, measurements of root growth and architecture are frequently overlooked in horticultural research (Wright and Wright, 2004). Regarding sweetpotato (Ipomoea batatas), Koshimizu and Nishida (1949) first suggested the link between lateral root (LR) development and storage root formation. Growing conditions during the transition from primary to secondary growth directly influence the onset of storage root formation, which is marked by the appearance of anomalous cambium, typically between 10 and $20 \mathrm{~d}$ (Togari, 1950). However, the direct relationship between LR development and anatomical cues associated with the onset of storage root formation has only recently been documented for the cultivar Beauregard (Villordon et al., 2012a). Linking root architecture attributes to storage root formation in sweetpotato paved the way for the systematic investigation of biotic and abiotic variables known to directly or indirectly influence sweetpotato storage root yield potential, including water availability (Villordon et al., 2012a), nitrogen variability (Villordon et al., 2013), virus presence (Villordon and Clark, 2014), and nematode infection (Villordon and Clark, 2018). Regarding sweetpotato in particular, there is increasing interest in understanding the biological and environmental variables that influence primary or main root length because this is directly related to the determination of storage root length and shape (Villordon et al., 2020). Minemba et al. (2019) reported evidence of variations in organic exudates among three sweetpotato cultivars in response to Pi levels. They used two cultivars native to Papua New Guinea and a Beauregard clone. They concluded that the sweetpotato relies more on organic acid exudation, arbuscular mycorrhizal fungi activity, and internal Pi remobilization, rather than on specialized root morphology, to acquire $\mathrm{Pi}$ in low Pi soils. Currently, there is limited information about root architectural adaptations to reduced or variable Pi availability at the onset of storage root formation 
Table 1. Description of sweetpotato cultivars used in the study.

\begin{tabular}{|c|c|c|c|c|c|}
\hline \multirow[b]{2}{*}{ Cultivar } & \multicolumn{3}{|c|}{ Storage root characteristics } & \multirow{2}{*}{$\begin{array}{l}\text { Relative U.S. } \\
\text { no. } 1 \text { yield potential }\end{array}$} & \multirow{2}{*}{$\begin{array}{l}\text { Cultivar release } \\
\text { information }\end{array}$} \\
\hline & Skin color & Flesh color & $\begin{array}{c}\text { Shape } \\
\end{array}$ & & \\
\hline $\begin{array}{l}\text { Bayou Belle } \\
(\mathrm{BB})^{\mathrm{y}}\end{array}$ & Red & Orange & Elliptic, slightly lobed, more blunt & $\geq 50 \%$ & LaBonte et al. (2013) \\
\hline $\begin{array}{l}\text { Beauregard } \\
\quad(\mathrm{BX}){ }^{\prime} \mathrm{B}-14{ }^{\prime}\end{array}$ & Light rose & Orange & Elliptic & - & Rolston et al. (1987) \\
\hline Evangeline (EV) & Rose & Deep orange & Elliptic to slightly more round & $\leq 25 \%$ & La Bonte et al. (2008b) \\
\hline Murasaki (MU) & Dark purple & White with yellow cast & Elliptic to round & $\leq 25 \%$ & La Bonte et al. (2008a) \\
\hline $\begin{array}{l}\text { Okinawan } \\
\qquad(\mathrm{OK})^{\mathrm{w}}\end{array}$ & Tan & Purple & Tapered, lobed & $<75 \%$ & \\
\hline Orleans (OR) & Light rose & Orange & Elliptic, more consistent shape & $\geq 25 \%$ & La Bonte et al. (2012) \\
\hline
\end{tabular}

${ }^{\mathrm{z}}$ Relative U.S. no. 1 storage root yield grade vs. cultivar 'Beauregard' harvested at 110-120 d as published in release notices and multiyear data from research plots at the Sweet Potato Research Station.

${ }^{\mathrm{y}}$ Formerly designated as '07-146'.

${ }^{\mathrm{x}}$ Clone 'B14' (La Bonte et al., 2004).

w'Okinawan' clone maintained by the Louisiana State University Agricultural Center sweetpotato foundation seed program. Originally sourced from a commercial nursery and subjected to virus testing procedures. This clone is presumed to be similar to the Okinawan cultivar grown in Hawaii.

for sweetpotato cultivars used in production systems where the crop is grown as an annual and typically harvested within 100 to $130 \mathrm{~d}$, such as sweetpotato-growing areas in North America and similar locations elsewhere. In these production systems, ARs that emerge during the first $10 \mathrm{~d}$ account for $86 \%$ of potential storage roots at harvest, and storage root formation takes place between 13 and 20 d (Villordon et al., 2009a, 2009b). Knowledge of biotic and abiotic variables associated with root architecture adaptations during the onset of storage root formation will lead to the development of methods and approaches that optimize management inputs and maximize yield potential of sweetpotato. The primary objective of this work was to generate species-specific information about root architectural responses to variations in $\mathrm{Pi}$ availability at the onset of storage root formation in sweetpotato.

\section{Materials and Methods}

Plant materials and experimental conditions. The greenhouse experiments were performed from 15 to 30 Dec. 2019 and from 1 to 15 Mar. 2020 in Chase, LA (lat. $32^{\circ} 6^{\prime} \mathrm{N}$, long. $91^{\circ} 42^{\prime} \mathrm{W}$ ). The following cultivars were used: Bayou Belle (BB), Beauregard $(\mathrm{BX})$, Evangeline (EV), Murasaki (MU), Okinawa (OK), and Orleans (OR). Cultivar descriptions and other pertinent information are presented in Table 1. The cultivars $\mathrm{BB}$ and $\mathrm{OR}$ were considered the check or control cultivars for storage root formation in the growing conditions used for the study. BB is a red-skin, orange-flesh cultivar developed for the processing market and is the highest storage root yielder, with the potential for early harvest relative to the other cultivars used in the study (Table 1). $\mathrm{OR}$ is a light rose-skin, orange-flesh cultivar that is gradually replacing $\mathrm{BX}$; for several years, it has been the main commercial orange-flesh, fresh-market cultivar and check cultivar in yield trials. Virus-tested generation 1 storage roots were bedded in plastic containers containing soilless media (Sungro; Sun Gro Horticulture, Bellevue, WA) and served as a source of transplants or vegetative cuttings for subsequent experiments. During each experiment, cuttings were set in 10-cmdiameter polyvinyl chloride (PVC) pots (height, $30 \mathrm{~cm}$ ) with detachable plastic bottoms. Each plastic bottom had five drain holes (diameter, $2 \mathrm{~mm}$ ). In addition, each PVC pot had four rows of side drain holes (diameter, $2 \mathrm{~mm} ; 3 \mathrm{~cm}$ apart within row) that were located diametrically opposite each other. These side drain holes were added to help reduce the incidence of a perched water table (Bilderback and Fonteno, 1987). Washed river sand was used as a growth substrate for all experiments. The diameter of the sand particles varied from 0.05 to $0.9 \mathrm{~mm}$, with the majority $(83 \%)$ in the range of 0.2 to $0.9 \mathrm{~mm}$. Extractable phosphorus of the substrate was 1 ppm using Mehlich 3 (Waypoint Analytical, Memphis, TN; complete laboratory analysis results of the growth substrate are shown in Supplemental Table 1). During all experiments, vegetative terminal cuttings with the following characteristics were used: length, 25 to $30 \mathrm{~cm}$; five to six fully opened leaves; diameter, $\approx 5 \mathrm{~mm}$ at the basal cut; and uniform distribution of nodes. The node associated with the fifth fully opened leaf is correlated with optimum storage root formation and should be included in the buried section of a cutting (Koshimizu and Nishida, 1949). To simulate field conditions where available Pi decreases over time and is subject to heterogenous distribution in the soil, $\mathrm{Pi}$ was provided as triple super phosphate (TSP; $0 \mathrm{~N}-46 \mathrm{P}-0 \mathrm{~K}$ ) instead of being applied in liquid form. For example, Hayes et al. (2004) reported that the root development response in wheat (Triticum aestivum) varied between field-based and solution culturebased screenings. Three Pi levels were used: 0 (low Pi), 0.17 (medium Pi), and 0.34 (high $\mathrm{Pi}$ g/pot TSP. The volume of the substrate was $1994 \mathrm{~cm}^{3}$ per pot, with a bulk density of $1.6 \mathrm{~g} \cdot \mathrm{cm}^{-3}$. The medium and high Pi levels were the equivalent of 100 and $200 \mathrm{~kg} \cdot \mathrm{ha}^{-1}$ of $\mathrm{P}_{2} \mathrm{O}_{5}$, respectively, assuming field soil bulk density of $1.3 \mathrm{~g} \cdot \mathrm{cm}^{-3}$ and plough depth of 30 $\mathrm{cm}$. We based our experimental Pi treatments on current commercial recommendations as well as past work involving sweetpotato. The medium $\mathrm{Pi}$ rate $\left(100 \mathrm{~kg} \cdot \mathrm{ha}^{-1} \quad \mathrm{P}_{2} \mathrm{O}_{5}\right)$ was within $30 \%$ of the current commercial recommendations for $\mathrm{P}_{2} \mathrm{O}_{5}$, which is 100 to 130 $\mathrm{kg} \cdot \mathrm{ha}^{-1}$ (Boudreaux, 2009), whereas the high $\mathrm{Pi}\left(200 \mathrm{~kg} \cdot \mathrm{ha}^{-1} \mathrm{P}_{2} \mathrm{O}_{5}\right)$ rate represents the upper limit of $\mathrm{P}_{2} \mathrm{O}_{5}$ rates that have been used in published and unpublished field trials (Jia et al., 2016; Jones, 1979). Before filling pots, the granular TSP was first ground into coarse powder and thoroughly mixed in the substrate using a portable concrete mixer. Pots that did not receive TSP were classified as low $\mathrm{Pi}$. All pots were provided with $0.5 \times$ Hoagland's solution 1 modified to remove Pi (Hoagland and Arnon, 1950) (Supplemental Table 2). During the critical establishment stage (first $3 \mathrm{~d}$ ), $190 \mathrm{~mL}$ of the nutrient solution was provided daily. After establishment, $190 \mathrm{~mL}$ was provided every other day until the completion of the study. This is the equivalent of providing $25 \mathrm{~mm} \cdot \mathrm{ha}^{-1}$ of water with each application. Cuttings were planted to a uniform depth of $6 \mathrm{~cm}$, with two to three nodes under the growth substrate surface, depending on the cultivar. All experiments were arranged as a randomized complete block repeated across planting dates. Unless otherwise indicated, there were four replicates in each experiment (one plant per pot $=$ one replicate). Plants were grown for $15 \mathrm{~d}$, after which near-intact root systems were collected.

Growth substrate moisture was measured with $\mathrm{ECH} 2 \mathrm{O}$ soil moisture sensors inserted vertically at a depth of 2 to $7 \mathrm{~cm}$ (Model EC5; Decagon Devices Inc., Pullman, WA). The moisture of the growing medium ranged from $5 \%$ to $9 \%$ volumetric water content (VWC), where $\approx 50 \%$ of field capacity (FC) was equal to $7 \%$ VWC. At saturation, the growing medium typically ranges from $12 \%$ to $14 \%$ VWC (Villordon et al., 2012a). The greenhouse temperature regime for the first $\mathrm{PD}$ (PD1) was $28^{\circ} \mathrm{C}$ (SD, 2.3) for $14 \mathrm{~h}$ (day) and $24{ }^{\circ} \mathrm{C}$ (sD, 3.3) for $10 \mathrm{~h}$ (night). The relative humidity (RH), measured hourly, was an average of $59 \%(\mathrm{SD}, 13.4)$. The temperature regime for the second $\mathrm{PD}(\mathrm{PD} 2)$ was $31{ }^{\circ} \mathrm{C}$ (SD, 2.2) for $14 \mathrm{~h}$ (day) and $27^{\circ} \mathrm{C} \mathrm{(SD,} \mathrm{2.7)} \mathrm{for}$ $10 \mathrm{~h}$ (night). The RH was an average of $53 \%$ (SD, 15.7). The temperature and $\mathrm{RH}$ were monitored at the canopy level using an integrated temperature and RH sensor (Model RHT; Decagon Devices Inc.). Supplementary lighting was provided using LED grow lights 

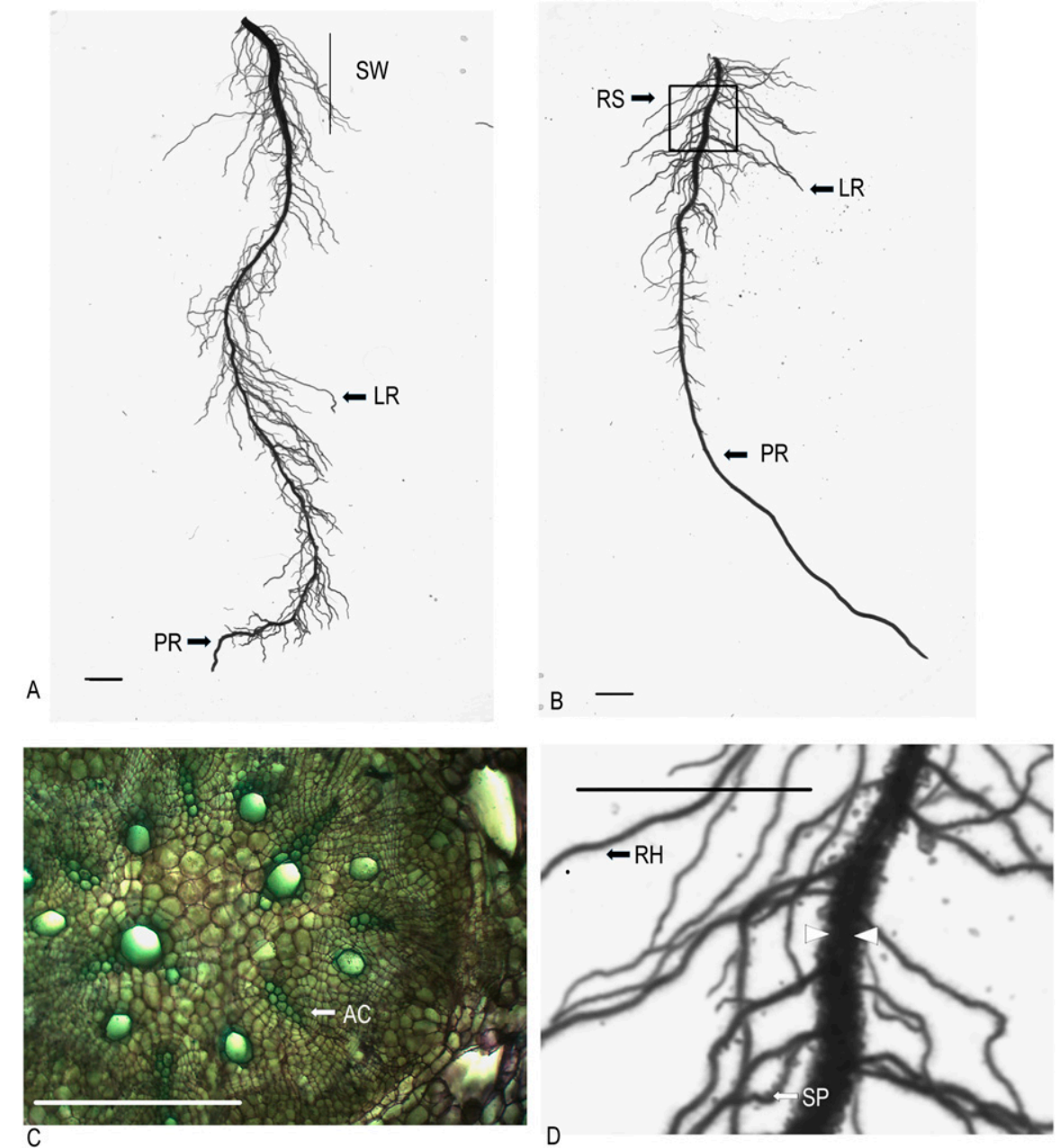

Fig. 1. Scanned image of 15-d-old 'Orleans' adventitious root showing pronounced swelling (SW) in the proximal 3- to 5-cm section of the primary or main root. A first-order lateral root (LR) is also labeled to clarify terminology used throughout this report. Scale bar $=1 \mathrm{~cm}(\mathbf{A})$. Scanned image of 15-d-old 'Murasaki' adventitious root with reduced lateral development and showing no evidence of SW. The primary root (PR) and a lateral root (LR) are also labeled for further clarification. RS indicates the section of root showing rhizosheath and sand particles adhering to lateral roots. Scale bar $=1 \mathrm{~cm}(\mathbf{B})$. Adventitious roots $(\mathbf{A}, \mathbf{B})$ were floated on waterproof trays and images were acquired using a dual-lens scanner equipped with the WinRhizo positioning system. Anatomical section of 15-d-old 'Bayou Belle' primary root showing presence of anomalous cambium (AC), confirming the onset of storage root formation. Scale bar $=0.5 \mathrm{~mm}(\mathbf{C})$. Zoomed-in view of the section labeled RS in (B) showing rhizosheath thickness indicated by arrowheads and details of sand particles (SP) adhering to root hairs $(\mathrm{RH})$. Scale bar $=1 \mathrm{~cm}(\mathbf{D})$.

(Lumigrow Inc., Emeryville, CA) for $14 \mathrm{~h}$ per day. Photosynthetic photon flux $(P P F)$ for PD1 ranged from 422 to $2731 \mathrm{mmol} \cdot \mathrm{m}^{-2} \cdot \mathrm{s}^{-1}$; $P P F$ for PD2 ranged from 582 to 3770 $\mathrm{mmol} \cdot \mathrm{m}^{-2} \cdot \mathrm{s}^{-1}$. $P P F$ was measured at the canopy level with a quantum sensor (Model QSO-S; Decagon Devices Inc.). These experimental approaches have been used to validate storage root initiation timing of $\mathrm{BB}, \mathrm{BX}$, and EV (Villordon et al., 2009a, $2009 \mathrm{~b}, 2012 \mathrm{a}$ ) and to measure root architecture responses to biotic and abiotic variables (Villordon and Clark, 2014; Villordon et al., 2012a, 2013).

Root architecture measurements and anatomical sampling. At harvest, the detachable plastic bottoms were removed and the pot was tilted to gradually remove the growth substrate and near-intact root system. Roots were initially placed on a flat surface and from 8 to $15 \mu \mathrm{m}$. Digital micrographs were obtained with a Motic Cam 2 (Motic Instruments Inc., British Columbia, Canada).

Measurements of root architectural attributes followed the procedures described in prior work involving the cultivars $\mathrm{BB}, \mathrm{BX}$, and EV (Villordon and Clark, 2014; Villordon et al., 2012a, 2013). Intact ARs that were $10 \mathrm{~cm}$ or longer in length were floated on waterproof trays and scanned using a specialized Dual Scan optical scanner (Regent Instruments Inc., Quebec, Canada). The acquisition and image analysis software was WinRHIZO Pro (v. 2009c; Regent Instruments Inc.). The image acquisition parameter was set to high accuracy (600 dpi; image size, $\approx 18 \mathrm{MB}$ ), and the analysis precision was set to high. Debris removal among scanned images was performed manually using the WinRHIZO Pro Edition working mode. Debris consisted mostly of sand particles and occasional broken root segments (length, $\leq 1 \mathrm{~cm}$ ).

In prior work using the cultivar BX, preset intervals in WinRHIZO were used to classify root classes (Villordon et al., 2012a, 2013). However, the variations in the complexity of root samples and overlapping root thickness led to classification errors among cultivar root classes in the current study. Hence, modifications of prior approaches were adopted for this work. For the purposes of this work, AR specimens with labeled sections in Fig. 1 were used to standardize terminology and clarify specific root class categories and attributes measured. First, PRL (Fig. 1A and B) was manually measured using the segmented line feature in ImageJ (Schneider et al., 2012). Second, total root length (TRL) was measured using WinRHIZO Pro (v. 2009c; Regent Instruments Inc.). Finally, first-order lateral root length (LRL) was calculated by subtracting the manual PRL measurements from the TRL. A separate analysis was performed using WinRHIZO to detect the length of primary root (PR) segments that were $\geq 3 \mathrm{~mm}$ to measure the incidence of storage root formation, defined as the onset of anomalous cambium development (Fig. 1A and C). An AR that failed to show evidence of anomalous cambium development is presented in Fig. 1B for comparison. Wilson and Lowe (1973) documented the onset of storage root formation in PR segments that were $1 \mathrm{~mm}$ in diameter. In the present study, anomalous cambium was detected in BB, $\mathrm{BX}$, and OR PR segments with diameters $\geq 2 \mathrm{~mm}$. However, many root segments had adhering rhizosheath (Fig. 1B and D) that was difficult to wash out using the standard washing sequence. Trial runs with multiple threshold levels were conducted using WinR$\mathrm{HIZO}$, and it was determined that using $3 \mathrm{~mm}$ as the threshold reduced misclassification errors without altering the results (data not shown). WinRHIZO was also used to estimate first-order lateral roots. LRD was calculated as the LRN per centimeter of the primary or main root (Borch et al., 1999).

Statistical analysis. Root length and counts were transformed using $\log 10$ and square root transformation, respectively. The 

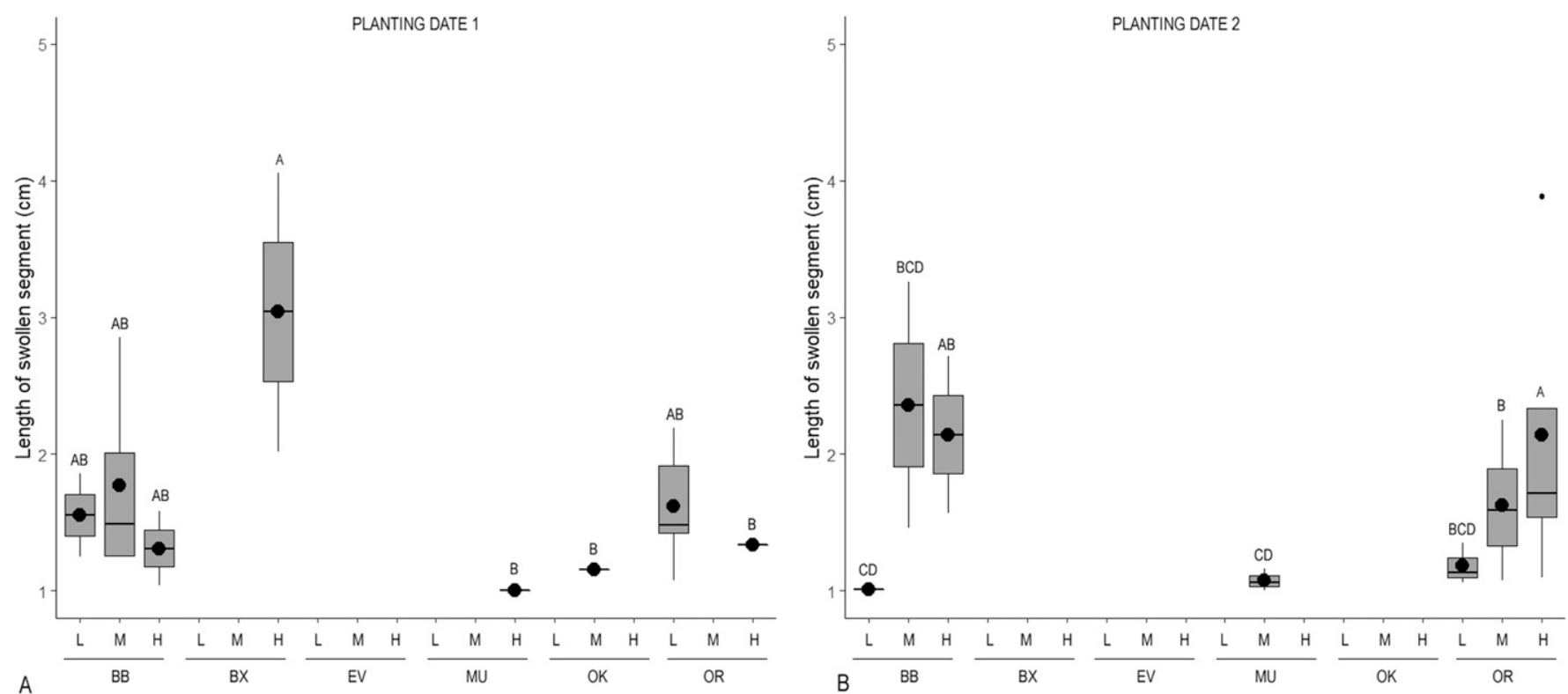

Fig. 2. Box plots of primary root segments with diameter $\geq 3 \mathrm{~mm}$ in sweetpotato cultivars grown in three phosphorus levels from two planting dates. Anatomical examinations of such segments show the onset of anomalous cambium development, which signifies the onset of storage root formation. Boxes represent the interquartile range (IQR; or middle 50\%) of values for each feature. Shaded circles represent mean values. Bold horizontal lines indicate median values. Upper box plot whiskers represent the last data point within the range of the $75 \%$ quantile $+1.5 \mathrm{IQR}$. Lower box plot whiskers represent the last data point within the range of the $25 \%$ quantile $-1.5 \mathrm{IQR}$. Dots represent outliers (values smaller or larger than the median \pm 1.5 -times the IQR). Mean comparisons of transformed data were performed; corresponding nontransformed values are shown. Boxes with different letters differ significantly at the 5\% level according to Fisher's least significant difference. Pi levels: $\mathrm{L}=$ low, $\mathrm{M}=$ medium, $\mathrm{H}=$ high. Cultivars: $\mathrm{BB}=$ 'Bayou Belle', $\mathrm{BX}=$ 'Beauregard', $\mathrm{EV}=$ 'Evangeline', $\mathrm{MU}=$ Murasaki, OK = 'Okinawa', OR = 'Orleans'.
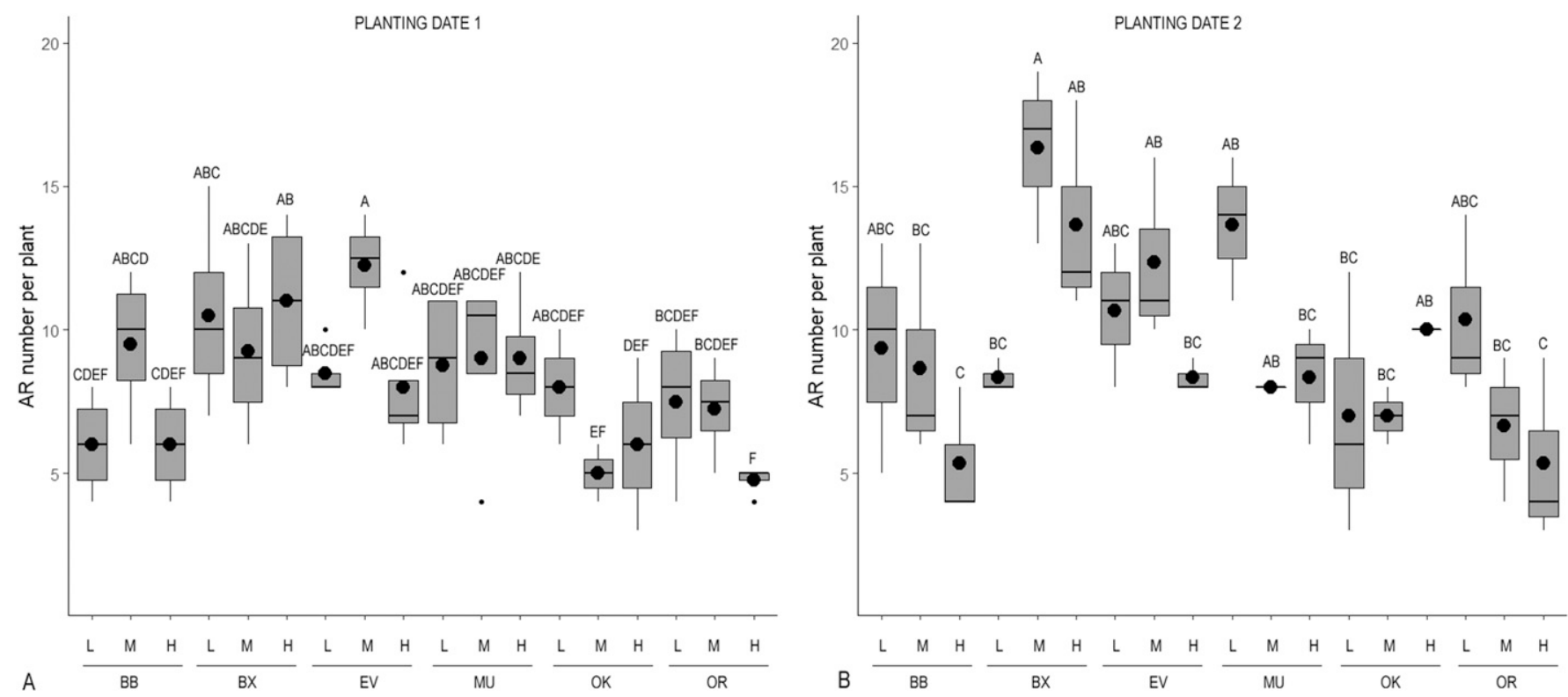

Fig. 3. Box plots of adventitious root number $\geq 10 \mathrm{~cm}$ in length in sweetpotato cultivars grown in three phosphorus levels from two planting dates. Boxes represent the interquartile range (IQR; or middle $50 \%$ ) of values for each feature. Shaded circles represent mean values. Bold horizontal lines indicate median values. Upper box plot whiskers represent the last data point within the range of the $75 \%$ quantile $+1.5 \mathrm{IQR}$. Lower box plot whiskers represent the last data point within the range of the $25 \%$ quantile $-1.5 \mathrm{IQR}$. Dots represent outliers (values smaller or larger than the median \pm 1.5 -times the IQR). Mean comparisons of transformed data were compared; corresponding nontransformed values are shown. Boxes with different letters differ significantly at the $5 \%$ level according to Fisher's least significant difference. Pi levels: $\mathrm{L}=$ low, $\mathrm{M}=$ medium, $\mathrm{H}=$ high. Cultivars: $\mathrm{BB}=$ 'Bayou Belle', $\mathrm{BX}=$ 'Beauregard', $\mathrm{EV}=$ 'Evangeline', $\mathrm{MU}=$ Murasaki, $\mathrm{OK}=$ 'Okinawa', $\mathrm{OR}=$ 'Orleans'.

unbalanced data set was analyzed using SAS Proc Mixed (SAS 9.4; SAS Inc., Cary, NC). Fisher's least significant difference test at the $0.05 P$ level was used to test for statistical significance. There was a significant $\mathrm{PD}$ and cultivar effect as well as cultivar $\times$ Pi level effect for all root attributes; hence, data were presented according to the PD. The R package ggplot2 (Wickham, 2009) was used to generate boxplots using $\mathrm{R}$ Studio (v. 1.2.1335; R Studio Inc., Boston, MA) with $\mathrm{R}$ version 3.6 ( $\mathrm{R}$ Development Core Team, 2019). The data presented were from nontransformed data.

\section{Results and Discussion}

The detection of anomalous cambium development in representative swollen primary root (PR) sections (diameter, $\geq 3 \mathrm{~mm}$ ) confirmed the onset of storage root formation at $15 \mathrm{~d}$ in the check or control cultivars 
(Fig. 1A and C). The cultivar BB presented evidence of early storage root formation across Pi levels with both PDs (Fig. 2). Anomalous cambium was also detected in OR, except for the medium Pi treatment with PD1. The lengths of the BB and OR swollen PR segments increased with added Pi for PD2. This response corroborates prior findings that increased $\mathrm{Pi}$ availability is associated with storage length increases in BB and BX (Villordon et al., 2018). The early onset of storage root formation in BB relative to other cultivars is consistent with past findings of storage root formation at $20 \mathrm{~d}$ in $\mathrm{BX}$ and $\mathrm{EV}$ in similar growing conditions (Villordon and Clark, 2018; Villordon et al., 2009a). Among the cultivars used in the current study, BB consistently produces relatively higher storage root yields in multiyear and multilocation field trials (Table 1) (LaBonte et al., 2013). These data corroborate observations that early storage root formation is an indicator of the relative productivity of sweetpotato cultivars (Firon et al., 2013). Wilson and Lowe (1973) reported the onset of anomalous cambium formation in West Indian cultivars in $\mathrm{PR}$ segments $\approx 1 \mathrm{~mm}$ in diameter. In the present study, we detected anomalous cambium in representative BB, $B X$, and OR PR segments $\geq 2 \mathrm{~mm}$ in diameter. However, the diameter of several root samples was artificially increased due to adhering rhizosheath (Fig. $1 \mathrm{~B}$ and D) that was difficult to wash out. Consequently, the threshold for classifying PR segments undergoing anomalous cambium development was increased to $3 \mathrm{~mm}$ to reduce misclassification errors without altering the results. Rhizosheath, the soil adhering to roots and, in some species, likely associated with root hair length (Delhaize et al., 2015), has been associated with increased Pi uptake in barley (Hordeum vulgare) (George et al., 2014) and wheat (Triticum aestivum) (James et al., 2016). Minemba et al. (2020) have provided evidence that rhizosheath bacteria mitigate sweetpotato responses to varying Pi availability. However, quantifying rhizosheath responses requires specialized equipment for precise measurements (George et al., 2014) and was beyond the scope of the current study.

Adventitious root number (ARN) varied among cultivars grown under specific $\mathrm{Pi}$ levels (Fig. 3). In general, BB had the lowest ARN relative to the other cultivars, but the magnitude of differences varied with the $\mathrm{Pi}$ level. Relative to $\mathrm{BB}$ grown in high $\mathrm{Pi}, \mathrm{EV}$ grown in medium Pi had $51 \%$ and $56 \%$ more ARN with PD1 and PD2, respectively. BX grown in high $\mathrm{Pi}$ had a $45 \%$ higher $\mathrm{ARN}$ compared with BB grown in low Pi with PD1, but no differences were detected with PD2. ARN variation at the onset of storage root formation among sweetpotato cultivars has been reported previously (Lowe and Wilson, 1974; Nakatani et al., 1989). Low Pi is associated with increased AR development in rice (Oryza sativa) and common bean (Phaseolus vulgaris) (Gonin et al., 2019). There is no available information regarding the subject of low Pi and ARN in sweetpotato and other vegetatively propagated root and tuber crops (Duque and Villordon, 2019). In the context of these findings, it has been proposed that genetic variations in AR emergence can be harnessed as an adaptation to low Pi soils (Miller et al., 2003). Cumulative evidence from maize (Zea maize) ARs, common bean basal roots, and white clover (Trifolium repens) lateral roots supports the hypothesis that low $\mathrm{Pi}$ increases ethylene sensitivity in plants (Song and Liu, 2015). We have previously documented that cultivar-specific AR emergence is mediated by differential ethylene sensitivity in BX and EV cultivars (Villordon et al., 2012b). Other than this finding, there is a general lack of understanding of the role of ethylene in low Pi responses in sweetpotato and other vegetatively propagated root and tuber crop species. Evidence from prior work (Lowe and Wilson, 1974; Ma et al., 2015) indicated that there is no direct correlation between total ARN per plant and final storage root number at harvest. Lowe and Wilson (1974) cited limiting factors that influenced final storage root yield, including assimilate production and transport. Green et al. (2005) used the concept of inter-LR competition when describing the reduction of soil volume exploited by developing Mediterranean shrub (Pistacia lentiscus) roots. Shao et al. (2018) reported that increased planting density in maize led to reduced nodal root number and inhibited LR growth. The relatively lower ARN for BB demonstrates the possible adaptive advantage of optimizing ARN to reduce underground root competition for resources and increase storage root formation potential. There is a significant gap in knowledge of how ARN is regulated and of the aforementioned ethylene sensitivity in sweetpotato cultivars. Such information is important for helping to clarify AR emergence in sweetpotato, especially in the context of findings of the possible role of ethylene in the AR response of well-studied plant species.

The PRL varied within and among cultivars across Pi levels (Fig. 4). For PD1, BX and $\mathrm{OK}$ grown in low $\mathrm{Pi}$ had $12 \%$ and $18 \%$ reductions in PRL, respectively, relative to roots grown in high $\mathrm{Pi}$; for $\mathrm{PD} 2, \mathrm{BX}$ and $\mathrm{OK}$ exhibited $21 \%$ and $30 \%$ reductions, respectively. OK grown in high $\mathrm{Pi}$ had $44 \%$ and $23 \%$ increases in PRL relative to $\mathrm{EV}$ and $\mathrm{MU}$, respectively, when grown in the same conditions. These results, in part, corroborate current findings regarding the role of genetic control of PRL response to low Pi availability in well-studied plant species. In Arabidopsis ecotype Col-0 and a recombinant in-bred population derived from Bay 0 and Sha wild accessions, low Pi availability was associated with reduced PRL (Sánchez-Calderón et al., 2006; Svistoonoff et al., 2007). However, it has also been reported that PRL response to low Pi varies in other Arabidopsis mutants and accessions (Chevalier et al., 2003; Sánchez-Calderón et al., 2006) as well as segregating populations within a plant species, including oilseed rape (Brassica napus)
(Shi et al., 2013). In contrast, Wang et al. (2008) reported increased PRL in narrow-leaf lupin (Lupinus angustifolius) grown in low $\mathrm{Pi}$ conditions. Narrow-leaf lupin is widely planted in infertile acidic soils in which $\mathrm{Pi}$ deficiency is one of the major limiting factors for plant growth (Wang et al., 2008). There has been substantial progress in identifying variables that determine PRL, but knowledge gaps persist in the understanding of the role of $\mathrm{Pi}$ in PRL determination and how $\mathrm{Pi}$ interacts with intrinsic and external variables (Abel, 2017)

There were limited and inconsistent LRL responses to varying Pi levels (Fig. 5). With $\mathrm{PD} 1, \mathrm{BX}$ grown in low Pi exhibited a $12 \%$ reduction in LRL compared with roots grown with Pi. With PD1, MU grown in high Pi had $41 \%$ and $16 \%$ reductions, respectively, relative to $\mathrm{BB}$ and $\mathrm{BX}$ grown in high $\mathrm{Pi}$. Reymond et al. (2006) documented contrasting LRL responses in a small panel of Arabidopsis accessions. Current available data support the hypothesis that LRL increases while PR decreases under conditions of low Pi availability (Bouain et al., 2016). We failed to detect such a relationship among the cultivars used in the study (data not shown). Prior work involving BX indicated that LRL was not directly associated with storage root formation in BX (Villordon et al., 2012a), suggesting that relatively longer LRL does not confer adaptive advantages associated with early storage root formation. We speculate that LRL is likely negatively selected for in-breeding programs, resulting in a lack of LRL variation among early storage root-forming (BB, BX, OR) compared to late storage root-forming $(\mathrm{EV}, \mathrm{MU}$, $\mathrm{OK}$ ) cultivars used in the study.

Relative to other cultivars, BB consistently exhibited high LRN across Pi levels and PDs (Fig. 6). OR LRN was also relatively high across PDs, except for the $38 \%$ reduction in low Pi relative to roots grown in high $\mathrm{Pi}$ in PD2. In prior work, ARs with high LRN showed evidence of storage root formation compared with ARs with low ARN from within the same BX plant (Villordon et al., 2012a). Borch et al. (1999) reported that low Pi reduced LRN in common bean. Jia et al. (2018) documented that maize lines with high LRN and LR density (LRD) were associated with increased $\mathrm{Pi}$ acquisition in low $\mathrm{Pi}$ soils relative to lines with reduced LRN and LRD. This is consistent with the hypothesis that increased LRN improves Pi acquisition under low Pi conditions and merits consideration for genetic improvement for $\mathrm{Pi}$ efficiency in maize and other crops (Jia et al., 2018).

BB consistently exhibited increased LRD relative to other cultivars across Pi levels (Fig. 7). OR also had relatively higher LRD but showed a $39 \%$ reduction in low Pi relative to roots grown in high $\mathrm{Pi}$ with PD2. OK LRD increased by $87 \%$ in roots grown in low $\mathrm{Pi}$ relative to high Pi with PD2. The LRD values for $\mathrm{BB}$ grown in high Pi are very similar to previously published LRD data for BX ARs showing evidence of anomalous cambium 

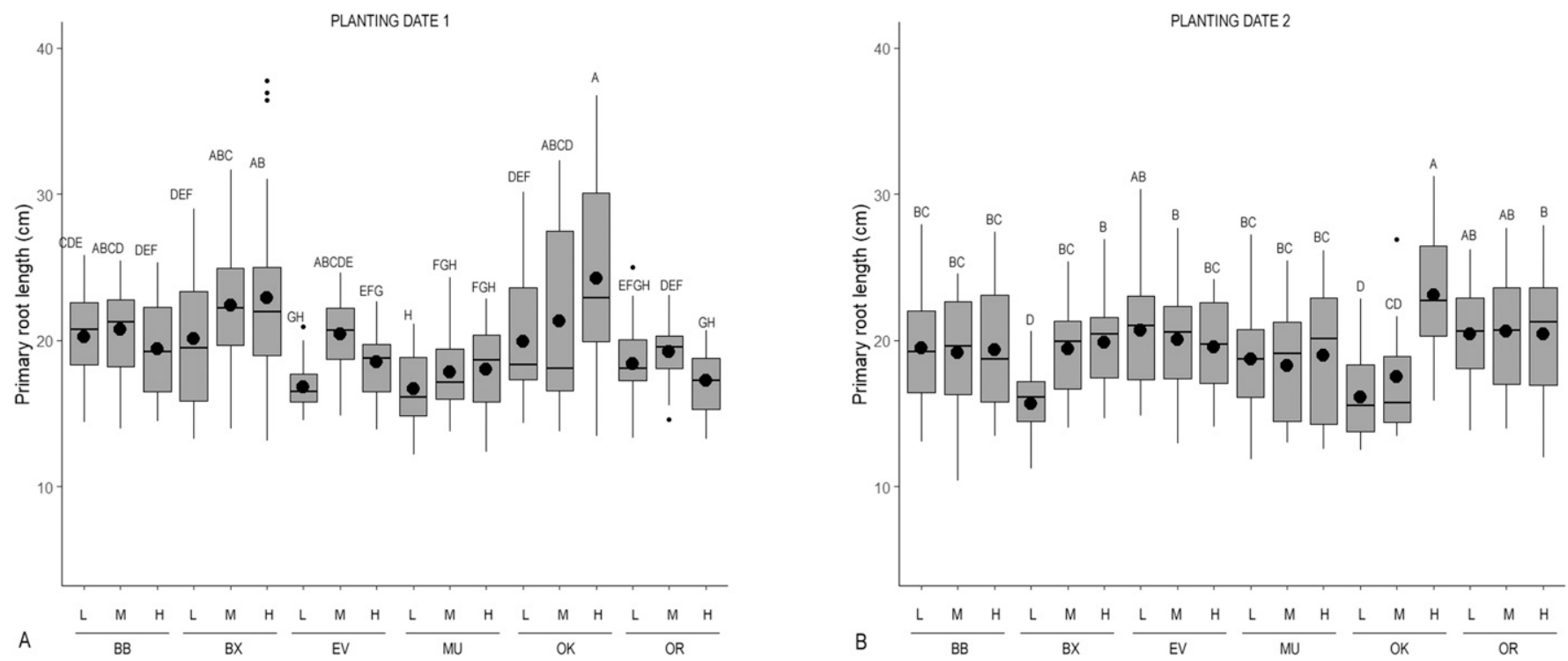

Fig. 4. Box plots of primary root length of sweetpotato cultivars grown in three phosphorus levels from two planting dates. Boxes represent the interquartile range (IQR; or middle 50\%) of values for each feature. Shaded circles represent mean values. Bold horizontal lines indicate median values. Upper box plot whiskers represent the last data point within the range of the $75 \%$ quantile + $1.5 \mathrm{IQR}$. Lower box plot whiskers represent the last data point within the range of the $25 \%$ quantile - 1.5 IQR. Dots represent outliers (values smaller or larger than the median \pm 1.5 -times the IQR). Mean comparisons of transformed data were performed; corresponding nontransformed values are shown. Boxes with different letters differ significantly at the 5\% level according to Fisher's least significant difference. Pi levels: $\mathrm{L}=$ low, $\mathrm{M}=$ medium, $\mathrm{H}$ = high. Cultivars: $\mathrm{BB}=$ 'Bayou Belle', $\mathrm{BX}=$ 'Beauregard', EV= 'Evangeline', $\mathrm{MU}=\mathrm{Murasaki}$, $\mathrm{OK}$ $=$ 'Okinawa', $\mathrm{OR}=$ 'Orleans'.
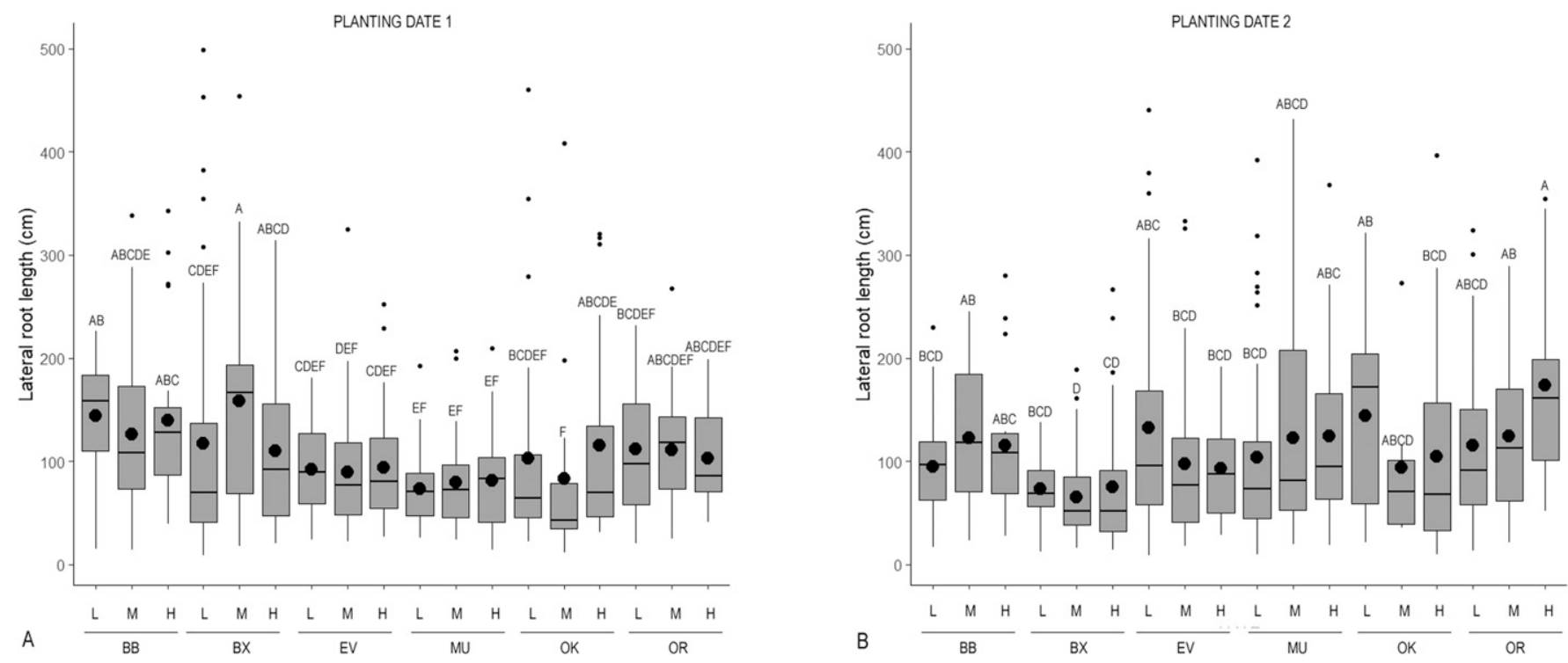

Fig. 5. Box plots of first-order lateral root length of sweetpotato cultivars grown in three phosphorus levels from two planting dates. Boxes represent the interquartile range (IQR; or middle 50\%) of values for each feature. Shaded circles represent mean values. Bold horizontal lines indicate median values. Upper box plot whiskers represent the last data point within the range of the $75 \%$ quantile $+1.5 \mathrm{IQR}$. Lower box plot whiskers represent the last data point within the range of the $25 \%$ quantile $-1.5 \mathrm{IQR}$. Dots represent outliers (values smaller or larger than the median \pm 1.5 -times the IQR). Mean comparisons of transformed data were performed; corresponding nontransformed values are shown. Boxes with different letters differ significantly at the 5\% level according to Fisher's least significant difference. Pi levels: $\mathrm{L}=$ low, $\mathrm{M}=$ medium, $\mathrm{H}=$ high. Cultivars: $\mathrm{BB}=$ 'Bayou Belle', $\mathrm{BX}=$ 'Beauregard', $\mathrm{EV}=$ 'Evangeline', $\mathrm{MU}=$ Murasaki, OK = 'Okinawa', OR = 'Orleans'.

development at $20 \mathrm{~d}$ (Villordon et al., 2012a). For well-studied plant species, it is generally accepted that increased LRD is associated with low Pi availability (López-Bucio et al., 2003). However, data are also available that show variable LRD responses to low $\mathrm{Pi}$ among ecotypes in Arabidopsis, and this response is also dose-dependent, (LópezBucio et al., 2003). In common bean, ethyl- ene reversed the effects of low Pi on LRD (Borch et al., 1999).

In Arabidopsis, LRD is associated with the timing of LR emergence relative to PR growth (Araya et al., 2016). Higher LRD values are directly related to increased LRN per unit PR length. Drew (1975) noted that LR emergence in barley progresses acropetally on the PR, and small differences in timing of LR emergence would give the appearance of a relatively large effect (for example, Fig. 1A vs. Fig. 1B). Regarding Arabidopsis, Dubrovsky et al. (2006) have presented evidence that LR primordia development occurred strictly acropetally, and that no de novo initiation events were found between already developed LRs or LR primordia. Arrested or slowly developing LR 

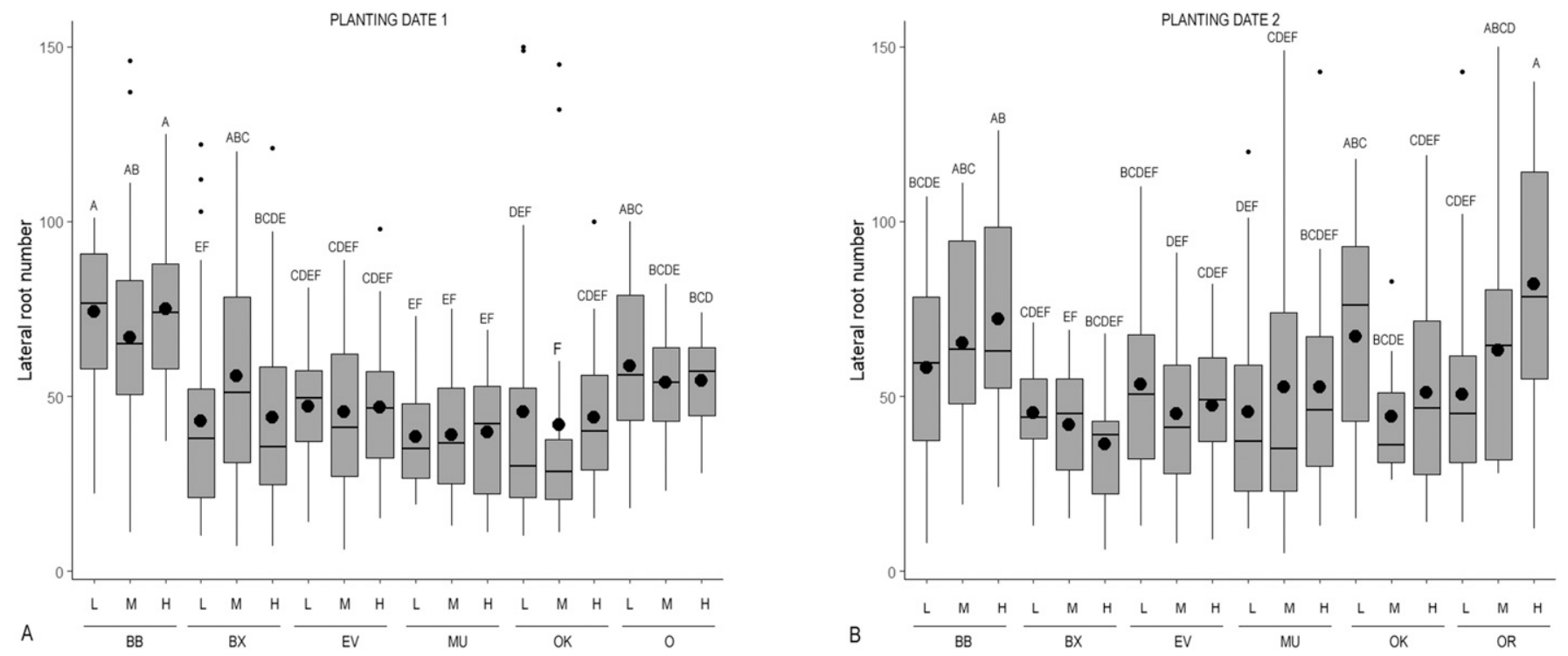

Fig. 6. Box plots of first-order lateral root number of sweetpotato cultivars grown in three phosphorus levels from two planting dates. Shaded circles represent mean values. Bold horizontal lines indicate median values. Boxes represent the interquartile range (IQR; or middle 50\%) of values for each feature. Upper box plot whiskers represent the last data point within the range of the $75 \%$ quantile $+1.5 \mathrm{IQR}$. Lower box plot whiskers represent the last data point within the range of the $25 \%$ quantile $-1.5 \mathrm{IQR}$. Dots represent outliers (values smaller or larger than the median \pm 1.5 -times the IQR). Mean comparisons of transformed data were performed; corresponding nontransformed values are shown. Boxes with different letters differ significantly at the $5 \%$ level according to Fisher's least significant difference. Pi levels: $\mathrm{L}=$ low, $\mathrm{M}=$ medium, $\mathrm{H}=$ high. Cultivars: $\mathrm{BB}=$ 'Bayou Belle', $\mathrm{BX}=$ 'Beauregard', $\mathrm{EV}=$ 'Evangeline', $\mathrm{MU}=$ Murasaki, OK = 'Okinawa', OR = 'Orleans'.
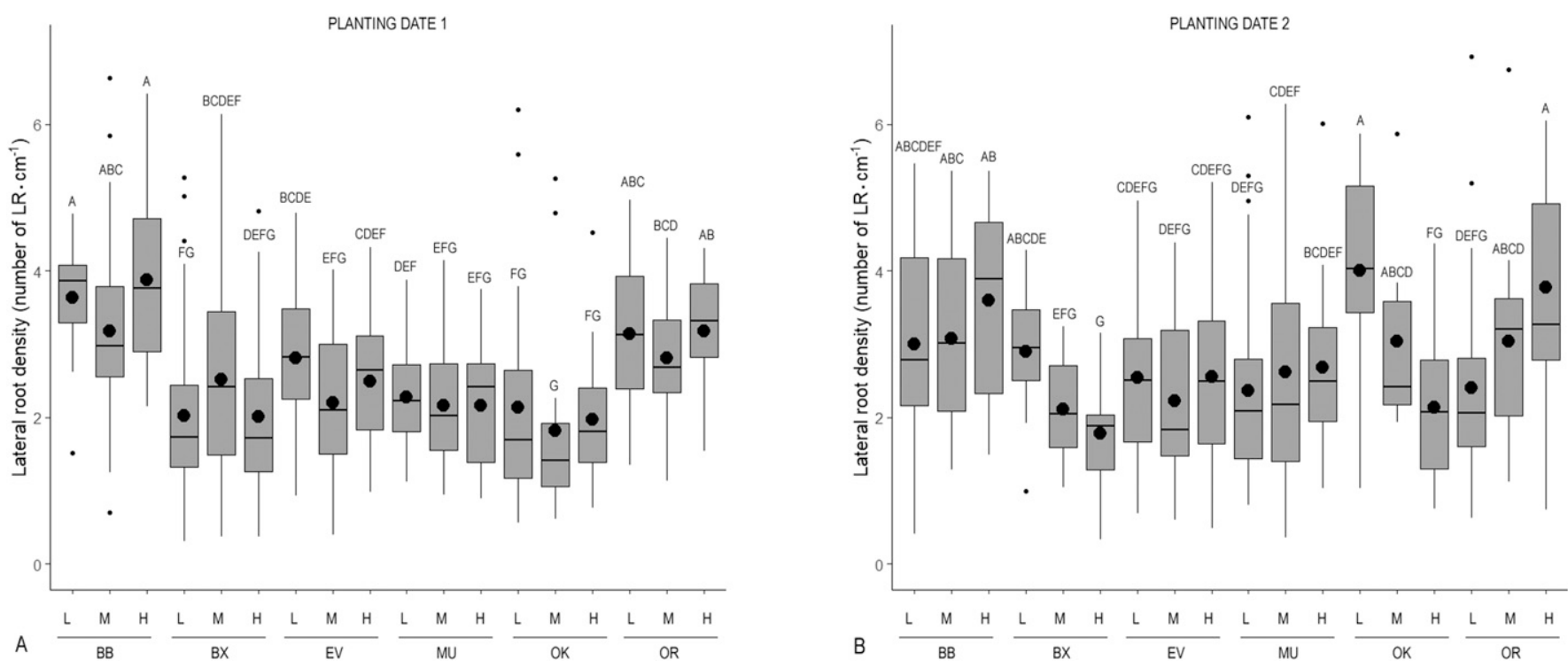

Fig. 7. Box plots of lateral root density of sweetpotato cultivars grown in three phosphorus levels from two planting dates. Shaded circles represent mean values. Bold horizontal lines indicate median values. Boxes represent the interquartile range (IQR; or middle 50\%) of values for each feature. Upper box plot whiskers represent the last data point within the range of the $75 \%$ quantile $+1.5 \mathrm{IQR}$. Lower box plot whiskers represent the last data point within the range of the $25 \%$ quantile $-1.5 \mathrm{IQR}$. Dots represent outliers (values smaller or larger than the median \pm 1.5 -times the interquartile range). Mean comparisons of transformed data were performed; corresponding nontransformed values are shown. Boxes with different letters differ significantly at the $5 \%$ level according to Fisher's least significant difference. Pi levels: $\mathrm{L}=$ low, $\mathrm{M}=$ medium, $\mathrm{H}=$ high. Cultivars: $\mathrm{BB}=$ 'Bayou Belle', $\mathrm{BX}=$ 'Beauregard', $\mathrm{EV}=$ 'Evangeline', $\mathrm{MU}=$ Murasaki, $\mathrm{OK}=$ 'Okinawa', $\mathrm{OR}=$ 'Orleans'.

primordia were found between developed LRs, and it was concluded that there was a narrow development window for LR initiation (Dubrovsky et al., 2006). Therefore, relatively higher LRD values are associated with the earlier onset and sustained development of LR on the PR axis compared with ARs with lower LRD (Fig. 1A and B). In this study, BB showed evidence of early storage root formation and exhibited higher LRN and LRD across Pi levels and PDs. The current experimental results and past findings (Villordon et al., 2012a) support the hypothesis that high LRN and LRD, along with optimized ARN, are root architectural traits associated with the competency for early storage root formation in sweetpotato cultivars. Selecting for early storage root-forming cultivars is an important consideration for sweetpotato crop improvement (Yanfu et al., 1989); however, there are practical and technical barriers to incorporating root traits in breeding programs (Villordon et al., 2014). The data also support the hypothesis that BB is less sensitive to low $\mathrm{Pi}$ conditions relative to the cultivars used in this study. These results are consistent with findings of other crop species regarding the existence of genetic variation for Pi efficiency (Heuer et al., 2017) and provide the basis for the possible selection for Pi efficiency in sweetpotato.

Further studies are needed to address the significant knowledge gaps regarding sweetpotato 
root system development responses to $\mathrm{Pi}$ availability in general and the roles of longdistance shoot signaling and hormones in particular. Furthermore, Pi remobilization from shoot to roots is another variable that modulates the response to low Pi (Veneklaas et al., 2012). Findings of the current study are consistent with the experimental results of Nassery (1970), who provided evidence that certain plant species will continue to grow using internal Pi stores if deprived of external Pi. Minemba et al. (2019) documented the response of two Papua New Guinea sweetpotato cultivars and a $\mathrm{BX}$ clone to varying $\mathrm{Pi}$ availability and reported that the tissue $\mathrm{P}$ concentration remained constant, even when Pi supply was low. They concluded that sweetpotato uses internal Pi efficiently and reported the lack of variation in root attributes among cultivars that were used in their study. These findings demonstrate how Pi omission studies of a vegetatively propagated crop species like the sweetpotato can be confounded if the Pi status of the source plant and cultivar are not accounted for (Villordon et al., 2018).

\section{Conclusion}

Although some of the findings corroborate data from model plant species, significant gaps exist in the understanding of sweetpotato root architectural responses to variable and low Pi availability, especially during the critical storage root formation phase. The experimental data suggest that environmental effects and genotype influence sweetpotato root architectural adaptations to variations in $\mathrm{Pi}$ availability. Our results also support the hypothesis that well-documented Pi-efficient root traits like high LRN and LRD are indirectly selected for in-breeding programs that focus on early storage root formation and stable yields across different environments. Follow-up studies with more diverse materials are needed. In model systems, long distance shoot-to-root signaling and, in particular, the roles of auxin and ethylene in mitigating responses to low $\mathrm{Pi}$ are well-described, but such information is lacking for sweetpotato.

\section{Literature Cited}

Abel, S. 2017. Phosphate scouting by root tips. Curr. Opin. Plant Biol. 39:168-177, doi: 10.1016/j.pbi.2017.04.016.

Araya, T., T. Kubo, N. von Wirén, and H. Takahashi. 2016. Statistical modeling of nitrogen-dependent modulation of root system architecture in Arabidopsis thaliana. J. Integr. Plant Biol. 58:254-265, doi: 10.1111/jipb.12433.

Bilderback, T.E. and W.C. Fonteno. 1987. Effects of container geometry and media physical properties on air and water volumes in containers. J. Environ. Hort. 5:180-182, doi: 10.24266/0738-2898-5.4.180.

Borch, K., T.J. Bouma, J.P. Lynch, and K.M. Brown. 1999. Ethylene: A regulator of root architectural responses to soil phosphorus availability. Plant Cell Environ. 22:425-431, doi: 10.24266/0738-28985.4.18010.1046/J.1365-3040.1999.00405.X.

Bouain, N., P. Doumas, and H. Rouached. 2016. Recent advances in understanding the molecu- lar mechanisms regulating the root system response to phosphate deficiency in Arabidopsis. Curr. Genomics 17:308-314, doi: 10.2174/ 2F1389202917666160331201812.

Boudreaux, J.E. 2009. Louisiana commercial vegetable production recommendations. Louisiana State University Agricultural Center, Louisiana Cooperative Extension Service. Pub. 2433. 30 July 2020. <https://www.lsuagcenter.com/NR/ rdonlyres/1A445217-3622-4161-ACF9-C0F28 FC6E753/59038/pub2433commvegetable BWLOWRES.pdf $\$$.

Chevalier, F., M. Pata, P. Nacry, P. Doumas, and M. Rossignol. 2003. Effects of phosphate availability on the root system architecture: Largescale analysis of the natural variation between Arabidopsis accessions. Plant Cell Environ. 26:1839-1850, doi: 10.24266/0738-2898-5.4. 18010.1046/j.1365-3040.2003.01100.x.

Crombez, H., H. Motte, and T. Beeckman. 2019. Tackling plant phosphate starvation by the roots. Dev. Cell 48:599-615, doi: 10.1016/ j.devcel.2019.01.002.

Delhaize, E., T.M. Rathjen, and C.R. Cavanagh. 2015. The genetics of rhizosheath size in a multiparent mapping population of wheat. $\mathrm{J}$. Expt. Bot. 66:4527-4536, doi: 10.1093/jxb/ erv223.

Dixon, M., E. Simonne, T. Obreza, and G. Liu. 2020. Crop response to low phosphorus bioavailability with a focus on tomato. Agronomy 10:617, doi: 10.3390/agronomy 10050617 .

Drew, M.C. 1975. Comparison of the effects of a localised supply of phosphate, nitrate, ammonium and potassium on the growth of the seminal root system, and the shoot, in barley. New Phytol. 75:479-490, doi: 10.1111/j.14698137.1975.tb01409.x.

Dubrovsky, J.G., G.A. Gambetta, A. HernandezBarrera, S. Shishkova, and I. Gonzales. 2006 Lateral root initiation in Arabidopsis: Developmental window, spatial patterning, density and predictability. Ann. Bot. (Lond.) 97:903915, doi: $10.1093 / \mathrm{aob} / \mathrm{mcj} 604$.

Duque, L.O. and A. Villordon. 2019. Root branching and nutrient efficiency: Status and way forward in root and tuber crops. Front. Plant. Sci. 10:237, doi: 10.3389/fpls.2019.00237.

Firon, N., D. LaBonte, A. Villordon, Y. Kfir, J. Solis, E. Lapis, T.S. Perlman, A. Doron-Faigenboim, A. Hetzroni, L. Althan, and L.A. Nadir. 2013. Transcriptional profiling of sweetpotato (Ipomoea batatas) roots indicates downregulation of lignin biosynthesis and up-regulation of starch biosynthesis at an early stage of storage root formation. BMC Genomics 14:460, doi: 10.1186/1471-2164-14-460.

George, T.S., L.K. Brown, L. Ramsay, P.J. White, A.C. Newton, A.G. Bengough, J. Russell, and W.T. Thomas. 2014. Understanding the genetic control and physiological traits associated with rhizosheath production by barley (Hordeum vulgare). New Phytol. 203:195-205, doi: 10.1111/ nph.12786.

Gonin, M., V. Bergougnoux, T.D. Nguyen, P. Gantet, and A. Champion. 2019. What makes adventitious roots? Plants 8:240, doi: 10.3390/ plants8070240.

Green, J.J., J.A. Baddeley, J. Cortina, and C.A. Watson. 2005. Root development in the Mediterranean shrub Pistacia lentiscus as affected by nursery treatments. J. Arid Environ. 61:112, doi: 10.1016/j.jaridenv.2004.09.001.

Gutiérrez-Alanís, D., J.O. Ojeda-Rivera, L. YongVillalobos, L. Cárdenas-Torres, and L. HerreraEstrella. 2018. Adaptation to phosphate scarcity: Tips from Arabidopsis roots. Trends Plant Sci. 23:721-730, doi: 10.1016/j.tplants.2018.04.006.
Hayes, J.E., Y.G. Zhu, T. Mimura, and R.J. Reid. 2004. An assessment of the usefulness of solution culture in screening for phosphorus efficiency in wheat. Plant Soil 261:91-97, doi: 10.1023/B:PLSO.0000035561.00460.8b.

Heuer, S., R. Gaxiola, R. Schilling, L. HerreraEstrella, D. Lopez-Arredondo, M. Wissuwa, E. Delhaize, and H. Rouached. 2017. Improving phosphorus use efficiency: A complex trait with emerging opportunities. Plant J. 90:868885, doi: $10.1111 /$ tpj. 13423 .

Hoagland, D.R. and D.I. Arnon. 1950. The waterculture method for growing plants without soil. California Agricultural Experiment Station, Circ. 347 (2nd ed.).

James, R.A., C. Weligama, K. Verbyla, P.R. Ryan, G.J. Rebetzke, A. Rattey, A.E. Richardson, and E. Delhaize. 2016. Rhizosheaths on wheat grown in acid soils: Phosphorus acquisition efficiency and genetic control. J. Expt. Bot. 67:3709-3718, doi: 10.1093/jxb/erw035.

Jia, X., P. Liu, and J.P. Lynch. 2018. Greater lateral root branching density in maize improves phosphorus acquisition from low phosphorus soil. J. Expt. Bot. 69:4961-4970, doi: 10.1093/ $\mathrm{jxb} / \mathrm{ery} 252$.

Jia, Z., P. Ma, X. Bian, X. Guo, and Y. Xie. 2016. Effects of different phosphorus application rates on dry matter accumulation and $\mathrm{N}, \mathrm{P}, \mathrm{K}$ absorption and utilization in sweetpotato. Southwest China J. Agr. Sci. 29:1358-1365.

Jones, L.G. 1979. The response of sweet potatoes to fertilizer phosphorus and potassium as related to levels of these elements available in the soil. LSU Agricultural Experiment Station Reports 788. 30 July 2020. <http://digitalcommons.lsu. edu/agexp/788>.

Koshimizu, T. and M. Nishida. 1949. On the relation between the distribution of free-auxin in the young sweet potato plant and its root tuber formation. Bot. Mag. Tokyo 62:735-736, doi: 10.15281/jplantres1887.62.146.

LaBonte, D., A. Villordon, T. Smith, and C. Clark. 2013. Sweetpotato plant named '07-146'. USA Patent USPP23785. July 30.

La Bonte, D.R., C.A. Clark, T.P. Smith, and A.Q. Villordon. 2012. 'Orleans' sweetpotato. HortScience 47:1817-1818, doi: 10.21273/HORTSCI. 47.12.1817.

La Bonte, D.R., A.Q. Villordon, C.A. Clark, P.W. Wilson, and C.S. Stoddard. 2008a. 'Murasaki29' sweetpotato. HortScience 43:1895-1896, doi: 10.21273/HORTSCI.43.6.1895.

La Bonte, D.R., P.W. Wilson, A.Q. Villordon, and C.A. Clark. 2008b. 'Evangeline' sweetpotato. HortScience 43:258-259, doi: 10.21273/HORTSCI. 43.1.258.

La Bonte, D., C. Clark, M. Hoy, A. Villordon, J. Cannon, M. Sistrunk, E. Freeman, and G. Roberts. 2004. Yield of four generations of virus-tested sweetpotato. HortTechnology 14: 320-322, doi: 10.21273/HORTTECH.14.3. 0320 .

Lobet, G., A. Paez-Garcia, H. Schneider, A. Junker, J.A. Atkinson, and S. Tracy. 2019. Demystifying roots: A need for clarification and extended concepts in root phenotyping. Plant Sci. 282:11-13, doi: 10.1016/j.plantsci. 2018.09.015.

Lopez-Arredondo, D.L., M.A. Leyva-González, S.I. González-Morales, J. López-Bucio, and L. Herrera-Estrella. 2014. Phosphate nutrition: Improving low-phosphate tolerance in crops. Annu. Rev. Plant Biol. 65:95-123, doi: 10.1146/ annurev-arplant-050213-035949.

López-Bucio, J., A. Cruz-Ramırez, and L. HerreraEstrella. 2003. The role of nutrient availability in regulating root architecture. Curr. Opin. 
Plant Biol. 6:280-287, doi: 10.1016/S13695266(03)00035-9.

Lowe, S.B. and L.A. Wilson. 1974. Comparative analysis of tuber development in six sweet potato (Ipomoea batatas (L.) Lam) cultivars: 1. Tuber initiation, tuber growth and partition of assimilate. Ann. Bot. 38:307-317, doi: 10.1093/oxfordjournals.aob.a084814

Ma, J., R. Aloni, A. Villordon, D. Labonte, Y. Kfir, H. Zemach, A. Schwartz, L. Althan, and N. Firon. 2015. Adventitious root primordia formation and development in stem nodes of 'Georgia Jet' sweetpotato, Ipomoea batatas. Amer. J. Bot. 102:1040-1049, doi: 10.3732/ ajb.1400505.

Miller, C.R., I. Ochoa, K.L. Nielsen, D. Beck, and J.P. Lynch. 2003. Genetic variation for adventitious rooting in response to low phosphorus availability: Potential utility for phosphorus acquisition from stratified soils. Funct. Plant Biol. 30:973-985, doi: 10.1071/FP03078.

Minemba, D., B.C. Martin, M.H. Ryan, E.J. Veneklaas, and D.B. Gleeson. 2020. Phosphate fertilizer alters carboxylates and bacterial communities in sweet potato (Ipomoea batatas (L.) Lam.) rhizosheaths. Plant Soil 454:245-260, doi: 10.1007/s11104-020-04646-6.

Minemba, D., D.B. Gleeson, E. Veneklaas, and M.H. Ryan. 2019. Variation in morphological and physiological root traits and organic acid exudation of three sweet potato (Ipomoea batatas) cultivars under seven phosphorus levels. Scientia Hort. 256:108572, doi: 10.1016/ j.scienta.2019.108572.

Nakatani, M., A. Oyanagi, Y. Watanabe, and M. Komeichi. 1989. Effects of soil temperatures on the rooting of cut-sprouts of sweet potato (Ipomoea batatas Lam.): II. Varietal differences in the optimum soil temperature for rooting and the rooting ability under the low soil temperature. Proc. Crop Sci. Soc. Jpn. 58:35-41, doi.org/10.1626/jcs.58.35.

Nassery, H. 1970. Phosphate absorption by plants from habitats of different phosphate status. II Absorption and incorporation of phosphate by intact plants. New Phytol. 69:197-203, doi: 10.1111/j.1469-8137.1970.tb04063.x.

Niu, Y.F., R.S. Chai, G.L. Jin, H. Wang, C.X. Tang, and Y.S. Zhang. 2013. Responses of root architecture development to low phosphorus availability: A review. Ann. Bot. 112:391-408, doi: $10.1093 / \mathrm{aob} / \mathrm{mcs} 285$.

Parry, G. 2018. Low phosphate puts auxin in the root hairs. Trends Plant Sci. 23:845-847, doi: 10.1016/j.tplants.2018.07.009.

R Development Core Team. 2019. R: A language and environment for statistical computing. Vienna, Austria: R Foundation for Statistical Computing.

Reymond, M., S. Svistoonoff, O. Loudet, L. Nussaume, and T. Desnos. 2006. Identification of QTL controlling root growth response to phosphate starvation in Arabidopsis thaliana. Plant Cell Environ. 29:115-125, doi: 10.1111/ j.1365-3040.2005.01405.x.

Roberts, T.L. and A.E. Johnston. 2015. Phosphorus use efficiency and management in agriculture. Resour. Conserv. Recycling 105:275-281, doi: 10.1016/j.resconrec.2015.09.013.
Rolston, L.H., C.A. Clark, J.M. Cannon, W.M. Randle, E.G. Riley, P.W. Wilson, and M.L. Robbins. 1987. 'Beauregard' sweet potato HortScience 26:1338-1339.

Sánchez-Calderón, L., J. López-Bucio, A. ChacónLópez, A. Gutiérrez-Ortega, E. HernándezAbreu, and L. Herrera-Estrella. 2006. Characterization of low phosphorus insensitive mutants reveals a crosstalk between low phosphorus-induced determinate root development and the activation of genes involved in the adaptation of Arabidopsis to phosphorus deficiency. Plant Physiol. 140:879-889, doi: 10.1104/pp.105.073825.

Schneider, C.A., W.S. Rasband, and K.W. Eliceiri. 2012. NIH Image to ImageJ: 25 years of image analysis. Nat. Methods 9:671-675, doi: 10.1038/ nmeth.2089.

Shao, H., T. Xia, D. Wu, F. Chen, and G. Mi. 2018. Root growth and root system architecture of field-grown maize in response to high planting density. Plant Soil 430:395-411, doi: 10.1007/ s11104-018-3720-8.

Shi, L., T. Shi, M.R. Broadley, P.J. White, Y. Long, J. Meng, F. Xu, and J.P. Hammond. 2013. High-throughput root phenotyping screens identify genetic loci associated with root architectural traits in Brassica napus under contrasting phosphate availabilities. Ann. Bot. 112: 381-389, doi: $10.1093 / \mathrm{aob} / \mathrm{mcs} 245$.

Simpson, R.J., A. Oberson, R.A. Culvenor, M.H. Ryan, E.J. Veneklaas, H. Lambers, J.P. Lynch, P.R. Ryan, E. Delhaize, F.A. Smith, and S.E. Smith. 2011. Strategies and agronomic interventions to improve the phosphorus-use efficiency of farming systems. Plant Soil 349: 89-120, doi: 10.1007/s11104-011-0880-1.

Song, L. and D. Liu. 2015. Ethylene and plant responses to phosphate deficiency. Front. Plant Sci. 6:796, doi: 10.3389/fpls.2015.00796.

Svistoonoff, S., A. Creff, M. Reymond, C. Sigoillot-Claude, L. Ricaud, A. Blanchet, L. Nussaume, and T. Desnos. 2007. Root tip contact with low-phosphate media reprograms plant root architecture. Nat. Genet. 39:792-796, doi: $10.1038 / \mathrm{ng} 2041$.

Togari, Y. 1950. A study of tuberous root formation in sweet potato. Bull. Nat. Agr. Exp. Sta. Tokyo 68:1-96. (Japanese with English summary).

Veneklaas, E.J., H. Lambers, J. Bragg, P.M. Finnegan, C.E. Lovelock, W.C. Plaxton, C.A. Price, W.R. Scheible, M.W. Shane, P.J. White, and J.A. Raven. 2012. Opportunities for improving phosphorus-use efficiency in crop plants. New Phytol. 195:306-320, doi: 10.1111/j.1469-8137.2012.04190.x.

Villordon, A., J.C. Gregorie, D. La, and D. Bonte. 2020. Direct measurement of sweetpotato surface area and volume using a low-cost 3D scanner for identification of shape features related to processing product recovery. HortScience 55:722-728, doi: $10.21273 /$ HORTSCI 14964-20.

Villordon, A. and C. Clark. 2018. Variation in root architecture attributes at the onset of storage root formation among resistant and susceptible sweetpotato cultivars infected with Meloidogyne incognita. HortScience 53:1924-1929, doi: 10.21273/HORTSCI1 0746-18.
Villordon, A., J.C. Gregorie, D. LaBonte, A. Khan, and M. Selvaraj. 2018. Variation in 'Bayou Belle' and 'Beauregard' Sweetpotato Root length in response to experimental phosphorus deficiency and compacted layer treatments. HortScience 53:1534-1540, doi: 10.21273/ HORTSCI13305-18.

Villordon, A.Q. and C.C. Clark. 2014. Variation in virus symptom development and root architecture attributes at the onset of storage root initiation in 'Beauregard' sweetpotato plants grown with or without nitrogen. PLoS One 9:e107384, doi: 10.1371/journal.pone.0107384.

Villordon, A.Q., I. Ginzberg, and N. Firon. 2014. Root architecture and root and tuber crop productivity. Trends Plant Sci. 19:419-425, doi: 10.1016/j.tplants.2014.02.002.

Villordon, A., D. LaBonte, N. Firon, and E. Carey. 2013. Variation in nitrogen rate and local availability alter root architecture attributes at the onset of storage root initiation in 'Beauregard' sweetpotato. HortScience 48:808-815, doi: 10.21273/HORTSCI.48.6.808.

Villordon, A., D. LaBonte, J. Solis, and N. Firon. 2012a. Characterization of lateral root development at the onset of storage root initiation in 'Beauregard' sweetpotato adventitious roots. HortScience 47:961-968, doi: 10.21273/HORTSCI. 47.7.961.

Villordon, A., C. Clark, D. LaBonte, and N. Firon. 2012b. 1-Methylcyclopropene has a variable effect on adventitious root emergence from cuttings of two sweetpotato cultivars. HortScience 47:1764-1767, doi: 10.21273/HORTSCI. 47.12.1764.

Villordon, A., D.R. LaBonte, N. Firon, Y. Kfir, E. Pressman, and A. Schwartz. 2009a. Characterization of adventitious root development in sweetpotato. HortScience 44:651-655, doi: 10.21273/HORTSCI.44.3.651.

Villordon, A., D.R. LaBonte, and N. Firon. 2009b. Development of a simple thermal time method for describing the onset of morpho-anatomical features related to sweetpotato storage root formation. Scientia Hort. 121:374-377, doi: 10.1016/j.scienta.2009.02.013.

Wang, B., J. Shen, C. Tang, and Z. Rengel. 2008. Root morphology, proton release, and carboxylate exudation in lupin in response to phosphorus deficiency. J. Plant Nutr. 31:557-570, doi: 10.1080/01904160801895084.

Wickham, H. 2009. ggplot2: Elegant graphics for data analysis. Springer, New York, https:// doi.org/10.1007/978-3-319-24277-4.

Wilson, L.A. and S.B. Lowe. 1973. The anatomy of the root system in West Indian sweet potato (Ipomoea batatas (L.) Lam.) cultivars. Ann. Bot. 37:633-643, doi: 10.1093/oxfordjournals.aob.a084729.

Wright, A.N. and R.D. Wright. 2004. The Horhizotron $^{\mathrm{TM}}$ : A new instrument for measuring root growth. HortTechnology 14:560-563, doi: 10.21273/HORTTECH.14.4.0560.

Yanfu, Y., T. Jialan, Z. Yunchu, and Q. Ruilian. 1989. Breeding for early-maturing sweet potato varieties, p. 67-82. In: K.T. Mackay, M.K. Palomer, and R.T. Sanico (eds.). Sweet potato research and development for small farmers. SEAMEO SEARCA, College Laguna, Philippines. 
Supplemental Table 1. Laboratory analysis results of the growth substrate used in the study.

\begin{tabular}{lc}
\hline Test & $\mathrm{mg} \cdot \mathrm{L}^{-1}$ \\
\hline Phosphorus & 1 \\
Potassium & 20 \\
Calcium & 197 \\
Magnesium & 30 \\
Sulfur & 8 \\
Boron & 0.1 \\
Copper & 0.1 \\
Iron & 16 \\
Manganese & 1 \\
Zinc & 0.1 \\
pH & 6.7 \\
Organic matter & $0.1 \%$ \\
\hline
\end{tabular}

Supplemental Table 2. Nutrient concentrations of the phosphorus-deficient nutrient solution used in the study.

\begin{tabular}{lc}
\hline Ion & Concn $\left(\mathrm{mg} \cdot \mathrm{L}^{-1}\right)^{2}$ \\
\hline $\mathrm{Ca}^{+2}$ & 100 \\
$\mathrm{Mg}^{+2}$ & 25 \\
$\mathrm{~K}^{+}$ & 118 \\
$\mathrm{NO}_{3}{ }^{-}$ & 105 \\
$\mathrm{SO}_{4}{ }^{-2}$ & 32 \\
$\mathrm{Fe}$ & 2.5 \\
$\mathrm{Mn}$ & 0.25 \\
$\mathrm{Cu}$ & 0.01 \\
$\mathrm{Zn}$ & 0.025 \\
$\mathrm{~B}$ & 0.25 \\
$\mathrm{Mo}$ & 0.0005 \\
$\mathrm{Cl}$ & 0.3 \\
\hline${ }^{\mathrm{z}}$ The composition of the nutrient solution is based \\
on half-strength solution 1 described by Hoagland \\
and Arnon (1950).
\end{tabular}

